\title{
Chemical Manipulation of Hsp70 ATPase Activity Regulates Tau Stability
}

\author{
Umesh K. Jinwal, ${ }^{1,2}$ Yoshinari Miyata, ${ }^{4}$ John Koren III, ${ }^{1,2}$ Jeffrey R. Jones, ${ }^{1,2}$ Justin H. Trotter, ${ }^{2}$ Lyra Chang, ${ }^{4}$ \\ John 0'Leary, ${ }^{1}$ David Morgan, ${ }^{2}$ Daniel C. Lee, ${ }^{2}$ Cody L. Shults, ${ }^{1,2}$ Aikaterini Rousaki, ${ }^{3}$ Edwin J. Weeber, ${ }^{2}$ \\ Erik R. P. Zuiderweg, ${ }^{3}$ Jason E. Gestwicki, ${ }^{3,4}$ and Chad A. Dickey ${ }^{1,2}$ \\ Departments of ${ }^{1}$ Molecular Medicine and ${ }^{2}$ Molecular Pharmacology and Physiology, USF Health Byrd Alzheimer's Institute, University of South Florida, \\ Tampa, Florida 33613, and Departments of ${ }^{3}$ Biological Chemistry and ${ }^{4}$ Pathology, Life Sciences Institute, University of Michigan, Ann Arbor, Michigan 48109
}

\begin{abstract}
Alzheimer's disease and other tauopathies have recently been clustered with a group of nervous system disorders termed protein misfolding diseases. The common element established between these disorders is their requirement for processing by the chaperone complex. It is now clear that the individual components of the chaperone system, such as $\mathrm{Hsp} 70$ and Hsp90, exist in an intricate signaling network that exerts pleiotropic effects on a host of substrates. Therefore, we have endeavored to identify new compounds that can specifically regulate individual components of the chaperone family. Here, we hypothesized that chemical manipulation of Hsp70 ATPase activity, a target that has not previously been pursued, could illuminate a new pathway toward chaperone-based therapies. Using a newly developed high-throughput screening system, we identified inhibitors and activators of $\mathrm{Hsp} 70$ enzymatic activity. Inhibitors led to rapid proteasome-dependent tau degradation in a cell-based model. Conversely, Hsp70 activators preserved tau levels in the same system. Hsp70 inhibition did not result in general protein degradation, nor did it induce a heat shock response. We also found that inhibiting Hsp70 ATPase activity after increasing its expression levels facilitated tau degradation at lower doses, suggesting that we can combine genetic and pharmacologic manipulation of $\mathrm{Hsp} 70$ to control the fate of bound substrates. Disease relevance of this strategy was further established when tau levels were rapidly and substantially reduced in brain tissue from tau transgenic mice. These findings reveal an entirely novel path toward therapeutic intervention of tauopathies by inhibition of the previously untargeted ATPase activity of Hsp70.
\end{abstract}

\section{Introduction}

In Alzheimer's disease (AD), the accumulation of amyloid plaques composed of $A \beta$ peptide is largely accepted as the pathogenic initiator, leading to intracellular accumulation of the microtubule-associated protein tau into tangles (Frautschy et al., 1991; Oddo et al., 2003). However, cognitive dysfunction and neuron loss, both in $\mathrm{AD}$ and transgenic mice that accumulate amyloid-type pathology, are critically linked to tau (Braak and Braak, 1991; Mukaetova-Ladinska et al., 2000; Roberson et al., 2007). Moreover, tau pathology is found in $\sim 15$ other neurodegenerative diseases, some of which are caused by mutations in the tau gene itself (Hardy and Orr, 2006). Thus, developing strategies to remove abnormal tau in symptomatic patients may be therapeutically beneficial; however, it is not yet clear which targets are best suited to accomplish this task.

Received July 13, 2009; revised Aug. 12, 2009; accepted Aug. 18, 2009.

C.A.D. acknowledges support from the Alzheimer's Association (NIRG-06-27099), the National Institute on Aging (AG031291), and the Abe and Irene Pollin Fund for CBD Research from CurePSP. J.E.G. acknowledges support from National Institutes of Health-National Institute of Neurological Disorders and Stroke (NS059690). E.R.P.Z. acknowledges support from the National Institutes of Health-National Institute of General Medical Sciences (GM063027). We thank Dr. Peter Seubert (Elan Pharmaceuticals) for contributing the 12 E8 antibody, Dr. Bingwei Lu for the Par1 expression plasmid, Dr. Benjamin Wolozin for the GSK3 $\beta$ expression plasmid, Dr. Peter Davies (Albert Einstein College of Medicine) for the PHF1 antibody, and Dr. M. Sherman for providing the Hsp70 expression plasmid.

Correspondence should be addressed to Dr. Chad A. Dickey, University of South Florida, 4001 East Fletcher Avenue, USF Health Byrd Alzheimer's Institute, MDC 36, Tampa, FL 33613. E-mail: cdickey@health.usf.edu. DOI:10.1523/JNEUROSCI.3345-09.2009

Copyright $\odot 2009$ Society for Neuroscience ～0270-6474/09/2912079-10\$15.00/0
Molecular chaperones, such as heat shock proteins Hsp70 and Hsp90, have been implicated in tau processing (Dou et al., 2003; Petrucelli et al., 2004; Shimura et al., 2004a,b; Dickey et al., 2006a,b, 2008; Luo et al., 2007; Carrettiero et al., 2009). Both Hsp70 and Hsp90 use ATP to regulate protein refolding (Slepenkov and Witt, 2002). The details of this mechanism and the effects of nucleotide exchange on Hsp70 structure and function have been established using mutagenesis, combined with structural and biophysical studies (Mayer et al., 2000; Brehmer et al., 2001). Briefly, ATP binding to the nucleotide-binding domain (NBD) of Hsp70 allosterically promotes a conformational change that initiates lowaffinity contact of a substrate/client with the substrate binding domain (SBD). ATP hydrolysis to ADP then causes an adjacent "lid" to close, facilitating high-affinity ( $\sim 10$-fold increase) substrate binding. When ADP is exchanged for ATP by an accessory nucleotide exchange factor (NEF), the lid opens, freeing the client. Despite recent progress, the mechanisms responsible for substrate fate decision making (i.e., degradation/release versus refolding/retention) are not yet clear and it is not known how Hsp70's ATPase activity is able to couple substrate affinity to folding outcomes.

In contrast to the extensive work on chemical inhibitors of Hsp90 ATPase function (Neckers, 2002; Dickey et al., 2007; Luo et al., 2007), chemical modulators of Hsp70 have proven more elusive, in part because of its comparatively low intrinsic ATPase activity $(<0.2 \mu \mathrm{mol} \mathrm{ATP} / \mu \mathrm{mol} / \mathrm{min}$ ) (Chang et al., 2008). Consequently, less is known about Hsp70 and its roles. However, 
A

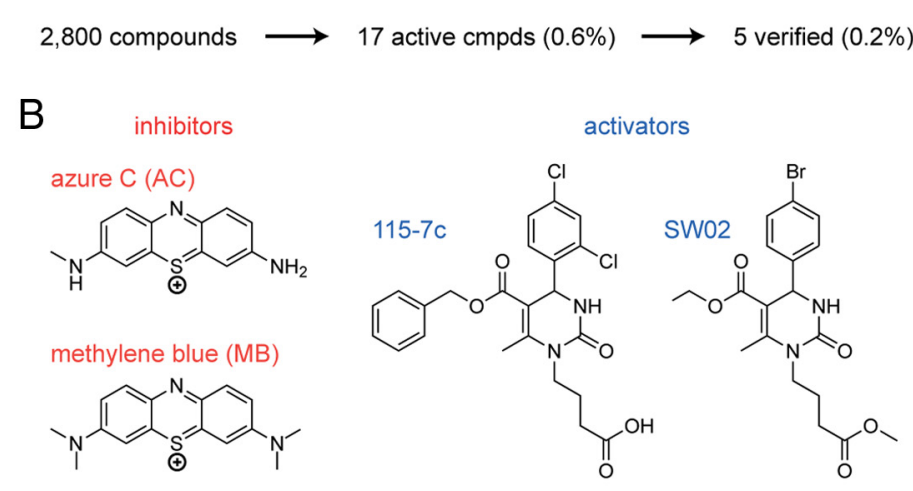<smiles>O=c1c(O)c(-c2cc(O)c(O)c(O)c2)oc2cc(O)cc(O)c12</smiles>

D
C

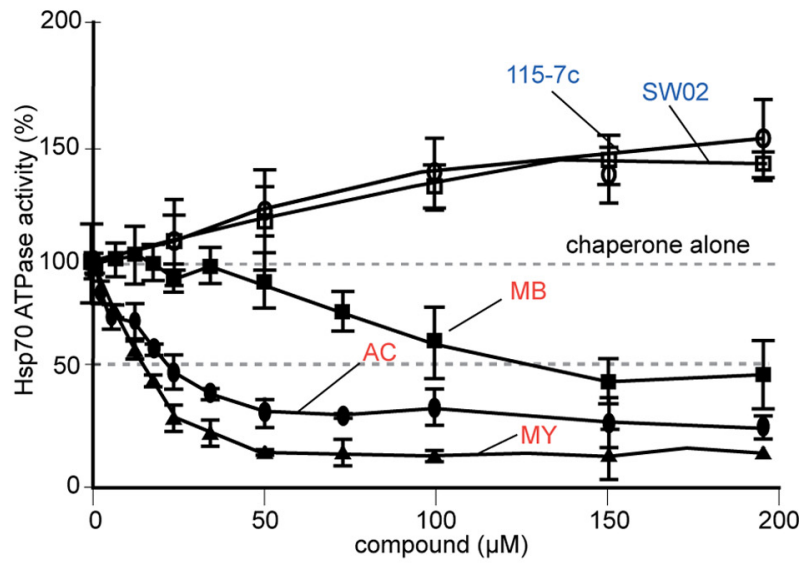

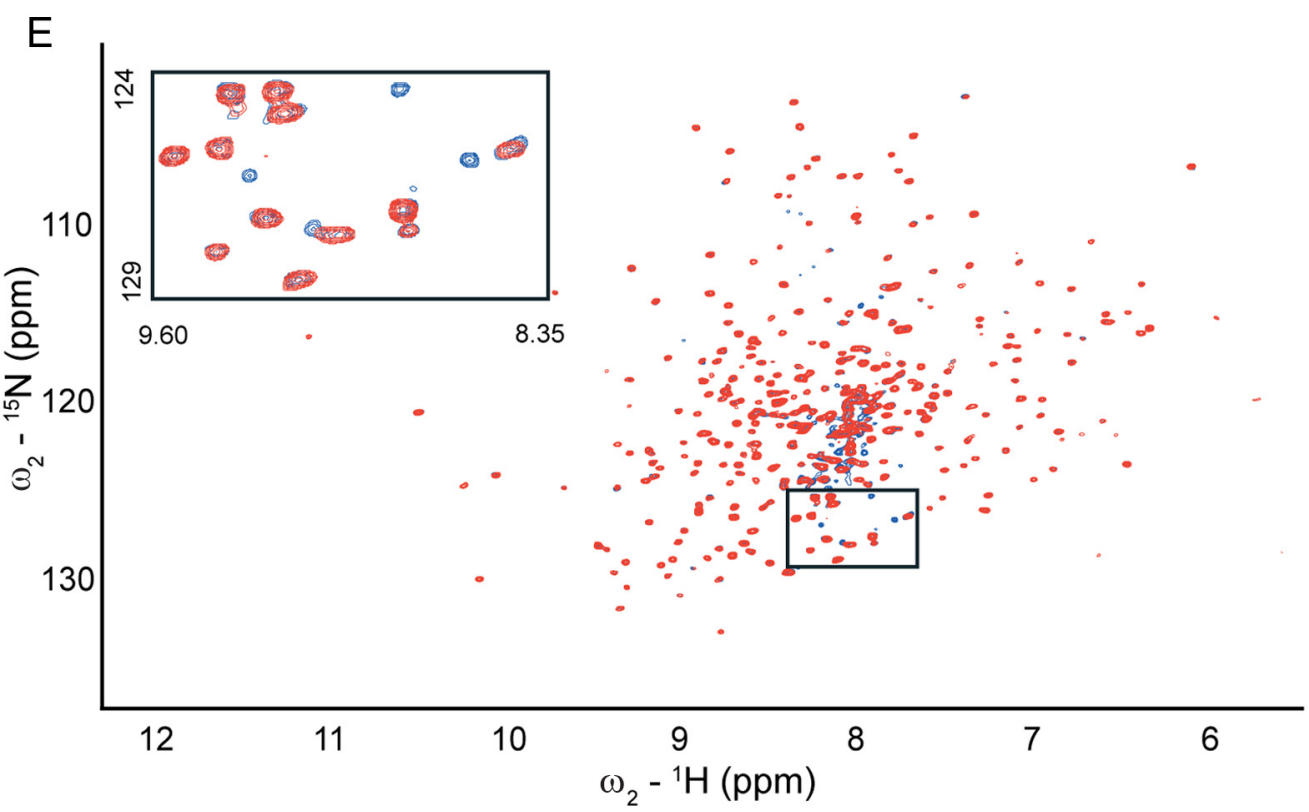

Figure 1. Identification of both activators and inhibitors of the ATPase activity of Hsp70 and confirmation of binding of the inhibitor MB by NMR. A, A high-throughput screen for ATP turnover mediated by human $\mathrm{Hsp70}$, followed by confirmation and dose dependence studies revealed five compounds $(0.2 \%)$ from a pilot collection of 2800 . $\boldsymbol{B}$, The chemical structures of the inhibitors and activators are shown. Note that inhibitors were identified from two distinct chemical classes: benzothiazines (MB, AC) and flavones (MY). C, Dose dependence studies confirm that the dihydropyrimidines $[115-7 \mathrm{c}(\bigcirc)$ and SW02 $(\square)]$ are activators of Hsp70-mediated nucleotide hydrolysis, while the benzothiazines $(\mathrm{MB}, \mathbf{\square} ; \mathrm{AC}, \mathbf{O})$ and $\mathrm{MY}(\mathbf{\Delta})$ inhibited this activity. Results are the average of triplicates and error is SD.D, EC ${ }_{50}$ values (IC $C_{50}$ for inhibitors, $\mathrm{EC}_{50}$ for activators) are represented in tabular format in micromolar concentrations \pm SD. Activators are indicated in blue and inhibitors in red. $\boldsymbol{E}$, Overlay of $15 \mathrm{~N}-1 \mathrm{H}$ HSQC-TROSY spectra of $100 \mu \mathrm{M} 15 \mathrm{~N}$-labeled human apo-Hsc70. The spectrum of Hsc70 without ligand (red) is superposed on the spectrum with one equivalent of MB. As seen in the inset, new crosspeaks arise from MB-bound Hsc70 (blue). cmpd, Compound.

genetic work in models of protein misfolding disorders has routinely documented strong correlations between Hsp70, not Hsp90, in limiting the progression of disease (Dou et al., 2003; Petrucelli et al., 2004). Using a sensitize, new screening assay that overcomes the challenges of weak ATPase activity (Chang et al., 2008), we identified several, first-generation inhibitors and activators of Hsp70 that have allowed us to explore the relationship between Hsp70 and tau. From these studies, some unexpected results have emerged that may change the way chaperone-based therapeutic approaches are being designed across fields.

\section{Materials and Methods}

Reagents, cell lines, and general methods. Methylthionine [azure C (AC)], tetramethylthionine [methylene blue $(\mathrm{MB})]$, thionin, and myricetin (MY) were purchased from Sigma and suspended in dimethylsulfoxide (DMSO). The dihydropyrimidines 115-7c and SW02 were synthesized as described (Wisén et al., 2008). Epoxomicin and 17-AAG were acquired from A.G. Scientific. All clones were in the pcDNA3.1 vector. siRNAs
(Qiagen) were transfected at $20 \mathrm{~nm}$. All antibodies were diluted in 5\% NFDM in TBS at 1:1000 with the exception of pS396/S404 tau, which was used at 1:100. Where pTau is indicated, pS396/S404 was the antibody used. PHF1 (pS396/S404 tau) was provided by Dr. Peter Davies (Albert Einstein College of Medicine, Bronx, NY). 12E8 (pS262/S356 tau) was provided by Dr. Peter Seubert (Elan Pharmaceuticals, South San Francisco, CA). The following antibodies were purchased from the company indicated in parentheses: $\alpha$-synuclein (Cell Signaling Technology), TDP-43 (Protein Tech), Hsp70 and HSF1 (Assay Designs), HA (Roche), actin (Sigma-Aldrich), Hsp40 (BD Transduction Laboratories), and Hsp27 and total tau (Santa Cruz Biotechnology). All cell lines were maintained according to ATCC guidelines. Stably transfected HeLa cells overexpressing wild-type $4 \mathrm{R} 0 \mathrm{~N}$ human tau were generated by clonal selection with G418 (Invitrogen).

Identification of chemical modulators of Hsp70. High-throughput screening of ATPase activity was performed as previously described (Chang et al., 2008). Briefly, hHsp70 (1 $\mu \mathrm{M})$ and a generic J-domain cochaperone (E. coli DnaJ; $1 \mu \mathrm{M})$ were prepared in assay buffer $(0.02 \%$ Triton X-100, $100 \mathrm{~mm}$ Tris-HCl, $20 \mathrm{~mm} \mathrm{KCl}$, and $6 \mathrm{~mm} \mathrm{MgCl}_{2}, \mathrm{pH}$ 7.4). 
A

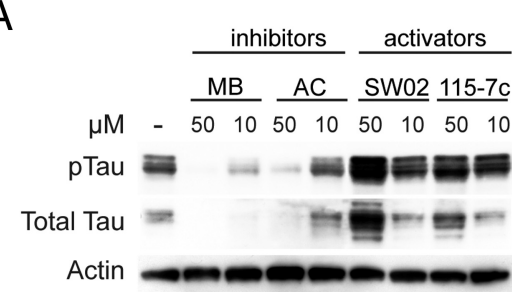

B

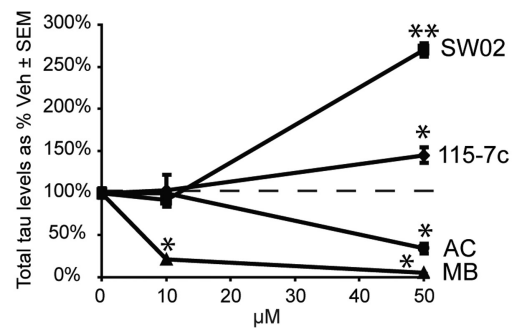

C
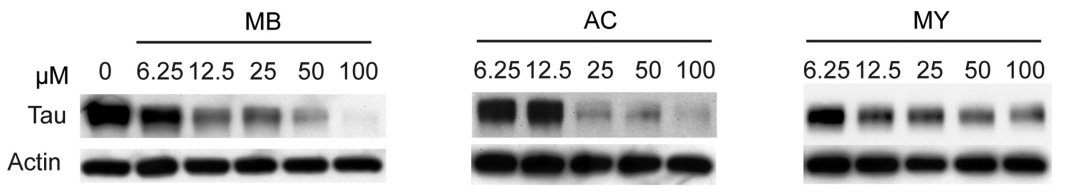

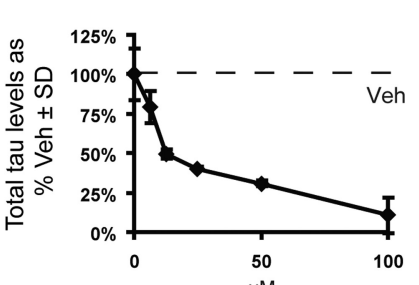

$\mathrm{D}$

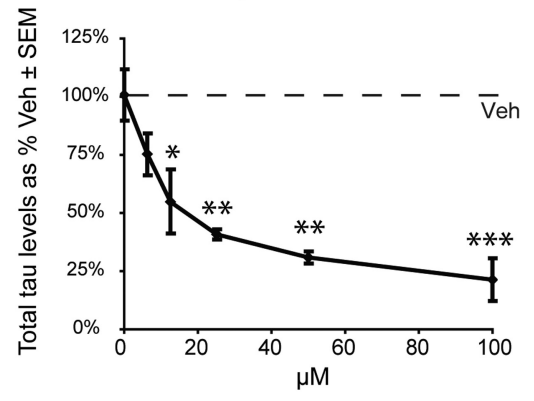

$\mathrm{F}$

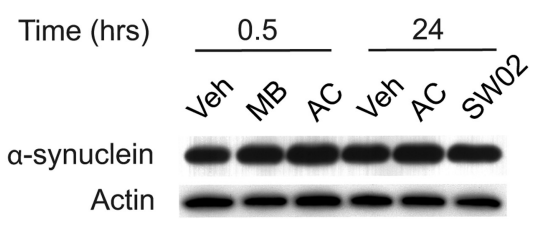

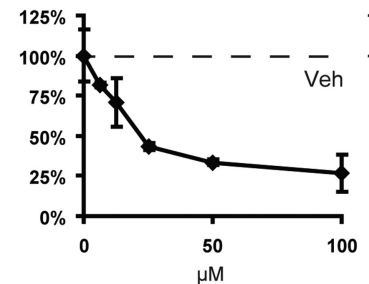

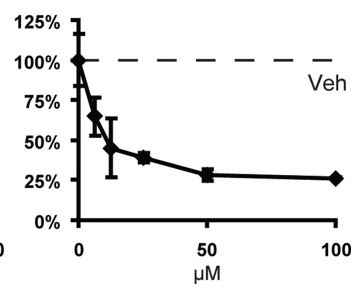

$\mathrm{E}$
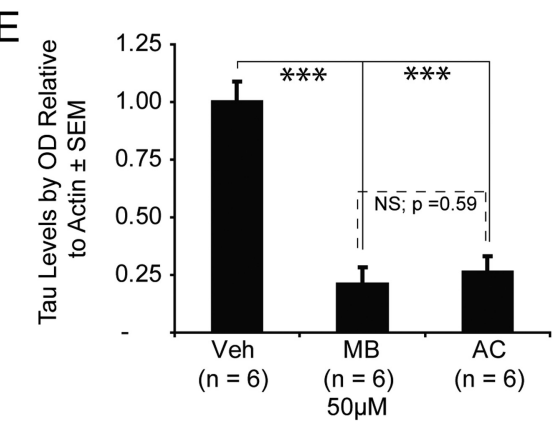

Figure 2. Inhibitors of Hsp70 decrease tau levels, and activators protect them. $A$, HeLa tau transfectants were treated for $24 \mathrm{~h}$ with Hsp70 inhibitors (MB or AC) or activators (SW02 or 115-7C). B, Quantification plots of the Western blots after actin normalization illustrate significant decreases in total tau levels at higher doses of $\mathrm{MB}(\mathbf{\Delta})$ or $\mathrm{AC}(\boldsymbol{)})$, while treatment with either 115-7c $(\bullet)$ or SW02 ( $\square$ ) increased tau levels. Analysis was performed using replicate blots. ${ }^{*} p<0.05,{ }^{* *} p<0.01$. C, HeLa cells stably transfected with human $4 R O N$ tau were treated with $M B$, $A C$, or $M Y$ for $3 \mathrm{~h}$ and harvested. Results are normalized to actin and compared with Veh. $\boldsymbol{D}$, Combining all three inhibitors for more complete statistical analysis of $\mathrm{Hsp} 70$ inhibition demonstrated that significant reductions in tau levels were achieved at $12.5 \mu \mathrm{M}$, and significance increased with higher concentrations. ${ }^{*} p<0.05$, ${ }^{* *} p<0.01,{ }^{* * *} p<0.001$. E, Statistical analyses using multiple experiments $(n=6)$ across cell models demonstrate that MB and $\mathrm{AC}$ each significantly and consistently reduce tau levels at $50 \mu \mathrm{m}$. Moreover, $\mathrm{MB}$ and $\mathrm{AC}$ were not significantly different from each other. ${ }^{*} p<0.05,{ }^{* *} p<0.01,{ }^{* * *} p<0.001$. F, HeLa cells were transfected with either $\alpha$-synuclein or TDP-43 and treated with indicated drugs [inhibitors in red, activators in blue, Hsp90 inhibitor (17AAG) and vehicle in black] for 30 min ( $\alpha$-synuclein) or $24 \mathrm{~h}$ (both $\alpha$-synuclein and TDP-43). Levels of either protein were unaffected by any treatment under these conditions (for quantitation, see supplemental Fig. S1, available at www.jneurosci.org as supplemental material).

This solution was aliquoted into 384-well plates with $1 \mathrm{~mm}$ ATP and either a query compound $(10 \mu \mathrm{M})$ or DMSO solvent control. After $3 \mathrm{~h}$ at $37^{\circ} \mathrm{C}$, malachite green reagent was used to detect liberated phosphate and the signal measured on a SpectraMax M5 (Chang et al., 2008). The pilot collection of compounds was comprised of the commercial MS2000 FDA-approved set (Spectrum) and an internally generated, focused collection of dihydropyrimidines (Wisén et al., 2008). The statistical parameters of the screen were similar to those previously reported for the prokaryotic Hsp70, DnaK ( $\mathrm{Z}$ factor $\sim 0.7 ; \mathrm{S} / \mathrm{N}>10$; CV $\sim 8 \%)$. Active compounds were defined as those with at least $30 \%$ activity: activators accelerated steadystate ATP hydrolysis at least $30 \%$, while inhibitors reduced this value. This criterion was selected because it represents 3 SDs of the DMSO control. Hits were subsequently subject to eight-point dose dependence verification in triplicate and the results analyzed with GraphPad PRISM.

Measurement of $M B$ binding to Hsp70 by NMR spectroscopy. The ${ }^{15} \mathrm{~N}-{ }^{1} \mathrm{H}$ HSQC-TROSY spectra (Salzmann et al., 1998) of $100 \mu \mathrm{M}{ }^{15} \mathrm{~N}$ labeled human $\mathrm{Hsc70}(1-381)$ was collected as previously described (Zuiderweg, 2002). Briefly, a $10 \times \mathrm{MB}$ stock solution was prepared in the same buffer as the NMR sample. Addition of 1 equivalent of $\mathrm{MB}$ caused several resonances corresponding to free Hsc70 to disappear. A second equivalent did not cause additional changes; thus, MB is believed to bind in a 1:1 stoichiometry to Hsc70 with slow release kinetics.

Measurements of tau levels in cell culture. Cells were transfected as previously described (Dickey et al., 2006a, 2007, 2008). Cell lysates and immunoprecipitates were analyzed by Western blots (Dickey et al., 2007). Briefly, cells were harvested in either Tris/ $\mathrm{NaCl}$ buffer containing protease and phosphatase inhibitor cocktails (for co-IP) with sonication or in MPER buffer (Pierce) containing protease and phosphatase inhibitor cocktails without sonication. For Sarkosyl- and SDS-insoluble protein analysis, $2 \mathrm{mg}$ of total protein were precleared at $14,000 \times g$ for 15 min (crude lysates) and soluble (S1) tau consisted of the supernatant from a $15 \mathrm{~min} 60,000 \times g$ spin. Pellets from the S1 spin were resuspended in a TBS/sucrose buffer with PMSF (Dickey et al., 2006b) and these pellets were incubated with either $1 \%$ Sarkosyl or $2 \%$ SDS for $1 \mathrm{~h}$ at $37^{\circ} \mathrm{C}$. Soluble and insoluble materials were analyzed by Western blot as previously described (Dickey et al., 2007).

Tau and Hsp70 interaction in the presence of $A T P-\gamma S$. HEK cells transfected with wild-type Hsp70 were lysed in assay buffer $(0.017 \%$ Triton $\mathrm{X}-100,100 \mathrm{~mm}$ Tris- $\mathrm{HCl}, 20 \mathrm{~mm} \mathrm{KCl}$, and 6 $\mathrm{mM} \mathrm{MgCl}_{2}, \mathrm{pH} 7.4$ ), with 15 strokes of a Dounce Homogenizer B. Cell lysates was supplemented with $0.5 \mu \mathrm{g}$ of purified recombinant Histagged human $4 \mathrm{R}$ Tau and treated with and without $0.5 \mathrm{~mm}$ ATP- $\gamma \mathrm{S}$ in $500 \mu \mathrm{l}$ total volume for $30 \mathrm{~min}$ at $37^{\circ} \mathrm{C}$ with gentle rocking. Twenty microliters of samples were removed for whole lysate measures. Twenty microliters of Ni-NT agarose (Qiagen) were added for pull-down coprecipitation of His-tagged tau/Hsp70 complexes. Samples were analyzed by Western blot.

Measurements of tau levels in brain slices and transgenic animals. Brain slices were prepared from 4-month-old rTg4510 mice and wildtype (non-Tg) littermates as previously described (Mirnikjoo et al., 2001) and treated with $\mathrm{MB}$ and $\mathrm{AC}$. Briefly, mice were decapitated and brains were removed and dropped in ice-cold cutting solution. Brains were cut midsagittally and were sectioned horizontally in ice-cold, oxygenated cutting solution at $400 \mu \mathrm{m}$. Sections were immediately transferred to 50:50 (cutting solution: artificial CSF, ACSF) at $27^{\circ} \mathrm{C}$ for $10 \mathrm{~min}$ and then equilibrated in $\mathrm{ACSF}$ at $37 \mathrm{C}$ for $30 \mathrm{~min}$. Sections were then transferred to warm, oxygenated ACSF containing drugs and incubated for $3 \mathrm{~h}$ at $37 \mathrm{C}$. 
Tissues were mechanically homogenized and analyzed by Western. Stereotaxic injections of AC or vehicle (Veh) into eight $\mathrm{rTg} 4510$ mice were performed as previously described (Wilcock et al., 2006). Briefly, bilateral hippocampal injections of $2 \mu \mathrm{l}$ of either a $10 \mathrm{~mm}$ solution of AC in $0.9 \%$ saline or $0.9 \%$ saline only were performed using a stereotaxic rig and a $10 \mu \mathrm{l}$ Hamilton syringe. Mice were killed $24 \mathrm{~h}$ after injection and brains were harvested and analyzed by Western blot.

Quantitation and statistical analyses of Western blots. Replicate densitometric values were obtained from repeated experiments, Western blots and densitometric variability. For replicate blots/experiments, SDs were calculated. For analyses across multiple models and tau species, as well as compilation of Hsp70 inhibitors, SEM was calculated where the $n$ was $\geq 3$. Statistical significance was determined with a heteroscedastic two-tailed Student's $t$ test.

\section{Results}

Using a newly described high-throughput screening (HTS) method, we evaluated a library of 2800 known bioactive compounds and identified five active compounds $(0.2 \%$ hit rate $)$ belonging to at least three chemical scaffolds (Chang et al., 2008) (Fig. 1A). These compounds either accelerated or reduced the ATPase activity of human Hsp70. The benzothiazine, $\mathrm{MB}$, its demethylated analog, AC (McKamey and Spitznagle, 1975), and the flavonol, MY, inhibited human Hsp70 by $>80 \%$ with $\mathrm{IC}_{50}$ values of 83,11 , and $12 \mu \mathrm{M}$, respectively (Fig. $1 B-D$ ). We were also able to identify activators of ATPase activity belonging to the dihydropyrimidine family (115-7c and SW02) that increased Hsp70 function by $\sim 45 \%$ with $\mathrm{EC}_{50}$ values of $\sim 120-150 \mu \mathrm{M}$. A direct interaction between $\mathrm{MB}$ and $\mathrm{Hsc70}$, binding was confirmed by NMR spectroscopy (Pellecchia et al., 2000). We estimated a binding affinity of $\sim 1 \mu \mathrm{M}$ from several well defined resonances in the HSQCTROSY spectrum of Hsc70's nucleotide-binding domain (Fig. 1E). Together, these experiments provided a suite of chemical probes, which we hypothesized, could be used to tune chaperone function.

We then explored the role of Hsp70 in HeLa cells overexpressing human tau using these compounds. $\mathrm{MB}$ and $\mathrm{AC}$ significantly reduced both total tau and phosphorylated tau (pTau), while treatment with $115-7 \mathrm{c}$ or SW02 led to accumulation of these species (Fig. $2 A$ ). Quantification of the blots confirmed that the inhibitors significantly decreased total tau levels at $50 \mu \mathrm{M}$ (Fig. $2 B$ ), while stimulating Hsp70 led to an increase of $~ 250-300 \%$ in total tau at $50 \mu \mathrm{M}$ (Fig. $2 \mathrm{~B}$ ). Thus, molecules identified as inhibitors of ATPase activity led to dose-dependent tau degradation (Fig. 2C) and activators caused its levels to increase. When inhibitors were combined and analyzed in aggregate, significant reductions in tau levels were observed in cells treated with 12.5 $\mu \mathrm{M}$ or more of inhibitor (Fig. $2 D$ ). We then analyzed the effects of $\mathrm{MB}$ and $\mathrm{AC}$ across a number (6 each) of independent experiments to determine the consistency of these data and found highly significant tau reductions at $50 \mu \mathrm{M}$ concentrations of each compound (Fig. 2E). Moreover, $\mathrm{AC}$ and $\mathrm{MB}$ were not significantly different from each other.

We next tested the response of two other disease-associated proteins to gauge the selectivity of these inhibitors for tau. We
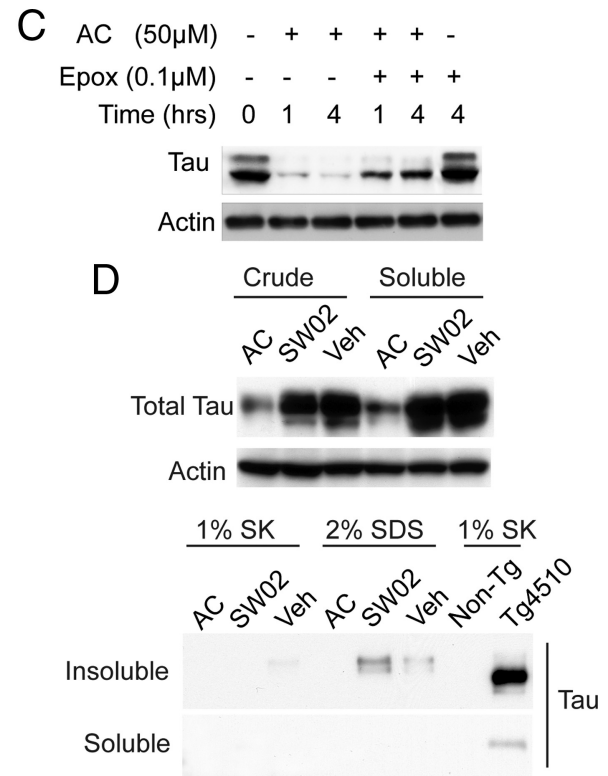
Tau

Figure 3. Nucleotide state of Hsp70 regulates tau binding and inhibitor-mediated reductions in tau occur via proteasomal

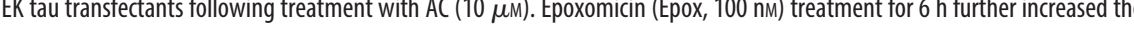
allpanels. 0 , Euivalent taulevelsareobserved treated with AC $(50 \mu \mathrm{m})$ or SW02 $(50 \mu \mathrm{m})$ for $1 \mathrm{~h}$. Absence of tau from soluble or insoluble fractions of Sarkosyl (SK) or SDS extracts prepared from insoluble pellets. Tg4510 brain Sarkosyl extract is shown as a procedural control.

investigated $\alpha$-synuclein, which is also an unstructured protein, but accumulates in Parkinson's disease, and we investigated TAR-DNA binding protein (TARDBP or TDP-43) that accumulates in a number of neurodegenerative diseases and has been identified as a cause for amyotrophic lateral sclerosis (ALS) (Josephs et al., 2008; Rutherford et al., 2008; Winton et al., 2008). We overexpressed both of these proteins in the same HeLa cell line that was used to study tau and treated with Hsp70 modifiers. Neither protein was sensitive to Hsp70 inhibitors (MB, AC, or myricetin), Hsp70 activators (SW02 or 115-7c), or the Hsp90 inhibitor, 17-AAG (Fig. 2F; supplemental Fig. S1, available at www.jneurosci.org as supplemental material). Although the underlying mechanisms are not yet clear, these findings suggested that tau is particularly sensitive to inhibition of Hsp70's ATPase activity.

Based on previous biophysical studies of Hsp70 structure and function, we expected that the observed changes in tau stability might be linked to changes in Hsp70's nucleotide state and subsequent changes in tau binding affinity. Consistent with this idea, addition of a nonhydrolyzable nucleotide analog, ATP- $\gamma \mathrm{S}$, reduced affinity of Hsp70 for tau in a coprecipitation assay (Fig. $3 A$ ). Moreover, coimmunoprecipitation from cells treated with Veh or AC \pm the proteasomal inhibitor, epoxomicin, showed that fewer Hsp70/tau complexes were present following AC treatment; however, ubiquitination of tau was increased (Fig. $3 B$; supplemental Fig. S2, available at www.jneurosci.org as supplemental material). We also found that epoxomicin abrogated AC-mediated tau reductions (Fig. 3C). This is consistent with previous genetic data showing that ATP-bound Hsp70 has a lower affinity for clients. These results also demonstrate that once clients are released from the low-affinity Hsp70/ATP complex, 


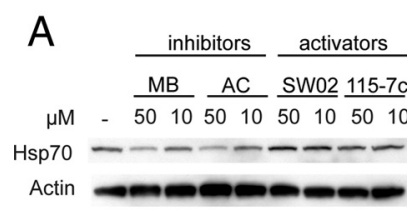

B

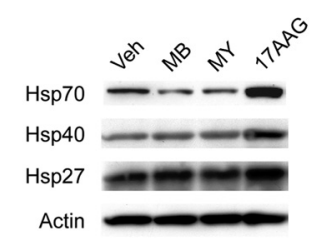

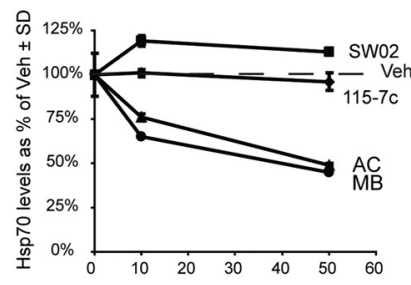

C

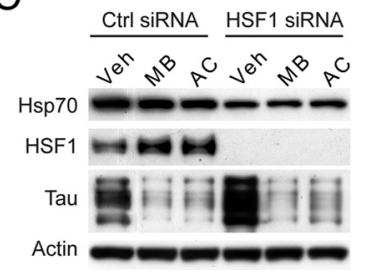

Figure 4. Reductions in tau are independent of a stress response or an increase in Hsp70 expression. $A$, HeLa tau transfectants were treated for $24 \mathrm{~h}$ with $\mathrm{Hsp} 70$ inhibitors (MB or $\mathrm{AC}$ ) or activators (SW02 or 115-7c) and Hsp70 levels were measured by Western blot. Quantification plots of the Western blots after actin normalization illustrate decreases in Hsp70 levels after treatment with $\mathrm{MB}(\boldsymbol{O})$ or $\mathrm{AC}(\boldsymbol{\Delta})$, while treatment with either 115-7c ( $\bullet$ ) or SW02 ( $\mathbf{\square})$ had no effect. SD was derived from replicate experiments. $\boldsymbol{B}$, Cells were treated with $\mathrm{MB}(10 \mu \mathrm{M})$, MY $(10 \mu \mathrm{M})$, or 17AAG $(1 \mu \mathrm{M})$ for $24 \mathrm{~h}$. Levels of Hsp70, Hsp40, and Hsp27 are shown from these Iysates. C, HeLa cells were transiently transfected with human wild-type tau and a nonsilencing (Ctrl) or HSF1 siRNA. These cells were then treated with MB or AC ( $50 \mu \mathrm{m})$ for $1 \mathrm{~h}$. Reductions in tau were similar in the presence of either siRNA. Statistical analyses across experiments $(n=4)$ indicated a trend ( $p=0.108)$ for Hsp70 reduction following Hsp70 inhibition.

they are delivered to the proteasome for ubiquitination. Although these results all suggested that tau is principally removed by the rapid function of the UPS or other chaperone-mediated degradation pathways, another possibility was migration of tau into an insoluble or aggregated structure (Berger et al., 2007). We therefore performed both traditional Sarkosyl and SDS extractions of cell lysates treated with these compounds and found no insoluble tau species (Fig. 3D). Thus, while other routes of cellular clearance may contribute to tau reductions following Hsp70 inhibition, conversion into an insoluble material is not facilitated.

Genetic evidence has previously suggested that increasing Hsp70 levels leads to increased binding to tau, which was necessary for CHIP-mediated ubiquitination and degradation (Petrucelli et al., 2004). It has also been shown that Hsp70 overexpression restores tau's association with the microtubules and preserves tau levels (Dou et al., 2003). Thus, to explore whether changes in tau levels are a result of changes in ATPase activity or changes in absolute Hsp70 levels, we measured chaperone induction in response to inhibitors and activators. Using Western blots against the stress-inducible Hsp70, we found that pharmacological manipulation did not increase expression levels (Fig. 4A). In fact, unlike cells treated with the Hsp90 inhibitor, 17-AAG, Hsp70 levels were actually slightly decreased following MB and MY treatment after $24 \mathrm{~h}$, while expression of other heat shock proteins were unchanged relative to control (Fig. 4B). Moreover, knockdown of HSF1 by siRNA did not abrogate the activity of $\mathrm{MB}$ or $\mathrm{AC}$ (Fig. 4C). While a cursory overview of these data would suggest that Hsp70 inhibitors were reducing Hsp70 levels, statistical analysis across multiple experiments revealed a trend but significance was not achieved ( $p=0.108$ ). Together, these results suggest that targeting the ATPase activity of Hsp70 controls tau accumulation independent of a global stress response.

Because the Hsp70 inhibitors did not increase chaperone levels, we wondered whether the levels of this protein might be
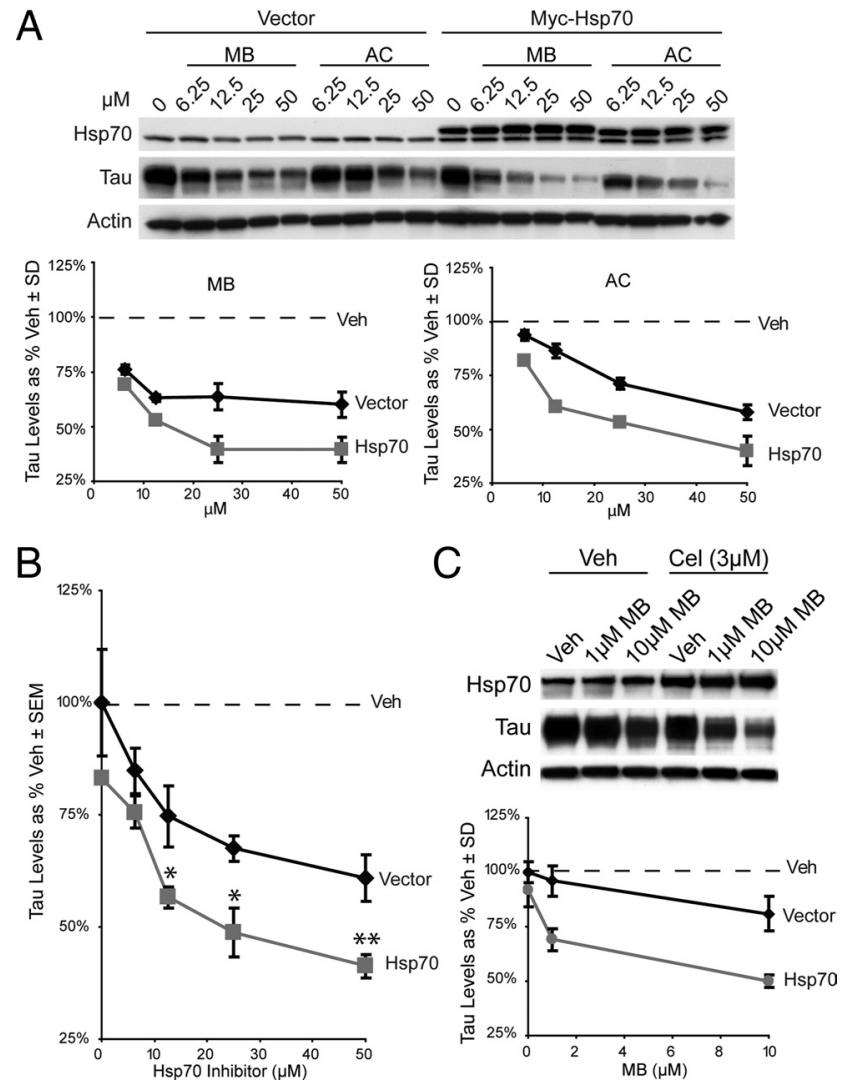

Figure 5. Increasing Hsp70 levels enhances Hsp70 inhibitor efficacy. $\boldsymbol{A}$, HeLa tau transfectants were cotransfected with vector or myc-tagged Hsp70 and cells were treated with the indicated dose of $\mathrm{MB}$ or $\mathrm{AC}$ for $1 \mathrm{~h}$. Consistent with a critical role for Hsp70, its overexpression dramatically improved the efficacy of MB and AC. Note that overexpression of Hsp70 alone had only mild effects on tau levels in the absence of inhibitors. Results are shown as a percentage of vehicle control after actin normalization compiled from replicate experiments. $\boldsymbol{B}$, Quantitation of both AC and MB from experiments in $\boldsymbol{A}$ shows overexpression of $H$ sp70 significantly increased Hsp70 inhibitor efficacy. Hsp70 overexpression alone did not significantly reduce tau levels. ${ }^{*} p<0.05,{ }^{* *} p<0.01$. C, HeLa tau transfectants were treated with $3 \mu$ m celastrol (Cel) for $24 \mathrm{~h}$ and then treated with indicated concentration of MB for $1 \mathrm{~h}$. Western analysis and quantitation shows that celastrol alone has minor effects on tau levels, whereas celastrol plus MB has much more potent effects than MB alone. Tau levels are represented as a percentage of actin by densitometry.

limiting for compound-mediated reductions in tau. To test this idea, cells were transiently transfected with myc-tagged Hsp70 and tau reductions by $\mathrm{AC}$ and $\mathrm{MB}$ were quantified (Fig. $5 A$ ). We found that increasing the levels of Hsp70 dramatically enhance the effectiveness of both $\mathrm{AC}$ and $\mathrm{MB}$ (tau levels were reduced $50 \%$ by only $12.5 \mu \mathrm{M}$ inhibitor). Interestingly, myc-Hsp70 overexpression alone only minimally affected tau levels (Fig. 5A). When analyzed in aggregate, Hsp70 inhibitors at concentrations $\geq 12.5 \mu \mathrm{M}$ were significantly more effective at clearing tau when Hsp70 was overexpressed (Fig. $5 B$ ). These findings suggest that the pool of Hsp70 is limiting for tau degradation in this specific model. Moreover, these studies suggest cells that express high levels of Hsp70, such as stressed cells, might be more sensitive to pharmacologic targeting of Hsp70. To explicitly investigate this possibility, we treated cells with celastrol, a compound that has previously been reported to robustly induce expression levels of Hsp70 (Westerheide et al., 2004). HeLa cells treated for $24 \mathrm{~h}$ with celastrol upregulated their Hsp70 levels approximately twofold to threefold, and these cells became sensitive to normally subeffective doses of MB (Fig. 5C) (1 $\mu \mathrm{M}$ reduced tau levels 25\%). Thus, 
by transiently increasing Hsp70 levels, we appeared to have produced more Hsp70/ tau complexes that become sensitive to changes in nucleotide turnover. The emphasis here was intentionally placed on "transient" upregulation of Hsp70 levels, since a concern with current chaperonebased therapies is that they induce heat shock protein expression (Zou et al., 1998). Certainly while transient upregulation of these proteins may be beneficial, long-term changes in gene expression elicited by compounds would likely have deleterious consequences during a chronic therapeutic course.

Because compounds that directly regulate ATPase function and multiprotein complexes often exert their effect quickly (Järv et al., 1980; Ward and O'Brian, 1992; Davidson and Varhol, 1995), we anticipated that tau reductions might be quite rapid. Indeed, we found that the rate of tau reduction in a stably transfected cell line was extremely fast, showing reductions within $5 \mathrm{~min}$ of treatment, consistent with acute enzymatic inhibition (Fig. $6 A, B)$. This decline continued over the hour (Fig. 6A, B). Rapid reductions were also observed for endogenous tau levels in both human [BE(2)-M17 and SHSY5Y] and murine (Neuro2a) neuroblastoma cell lines that do not overexpress tau (Fig. 6C). Analysis of drug efficacy across cell lines demonstrated significant decreases in tau levels after 5 min following Hsp70 inhibitor treatment, and highly significant reductions after $60 \mathrm{~min}$ (Fig. 6D). Moreover, the flavonol, MY, also rapidly reduced tau levels, with reductions evident as early as $1 \mathrm{~h}$ (Fig. 6 E). Interestingly, tau levels began to rebound after $6 \mathrm{~h}$, indicative of the highly unstable nature of flavonoid compounds (Boulton et al., 1999). These data gave us further confidence that the compounds might be directly inhibiting Hsp70 activity and facilitating chaperone-mediated tau turnover.

Since the major body of work describing tau dysfunction in $\mathrm{AD}$ focuses on its hyper-phosphorylation, we investigated whether overexpression of two kinases that are known to promote tau hyperphosphorylation at distinct residues could affect Hsp70 inhibitor efficacy toward tau. HeLa cells stably overexpressing human wild-type tau were transfected with either glycogen synthase kinase $3 \beta(\mathrm{GSK} 3 \beta)$ or microtubule affinity regulating kinase 2 (MARK2/Par1) for $24 \mathrm{~h}$. These cells were then treated with MB, AC, or SW02 for $1 \mathrm{~h}$ and harvested. Tau phosphorylated at S396/ S404 was significantly reduced with the inhibitors, regardless of which kinase was overexpressed (Fig. 7A). Interestingly, in cells overexpressing MARK2/Par1, tau phosphorylated at S262/S356 was not affected by the inhibitors, consistent with previous data suggesting that MARK2/Par1 can essentially make tau chaperone resistant (Dickey et al., 2006a, 2007) (Fig. 7A). Total tau levels were also reduced in all cases. SW02 did not increase tau levels following the short $1 \mathrm{~h}$ incubation. Next, using three tau mutants that are known to cause frontotemporal dementia with parkinsonism linked to chromosome 17 (FTDP17) or progressive

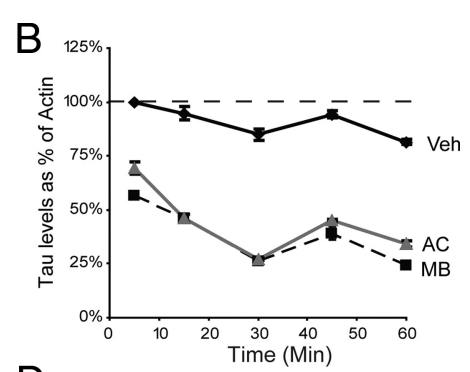

$\mathrm{D}$
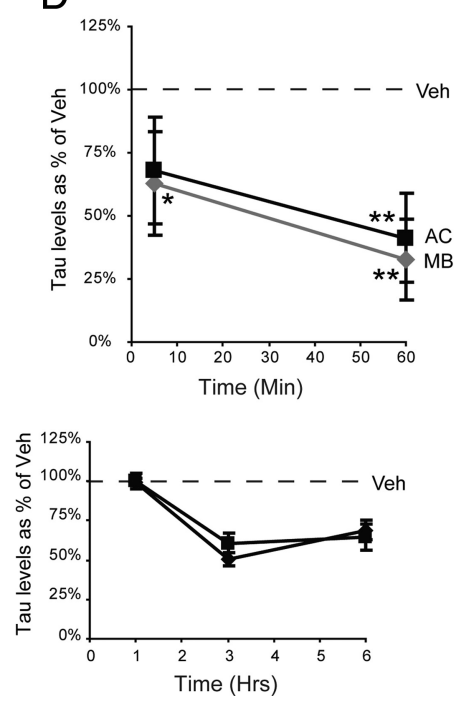

Figure 6. Tau is rapidly degraded in response to Hsp70 inhibitors. $A$, Evaluation of the effects of $M B$ and $A C$ over $1 \mathrm{~h}$ in stable tau HeLa transfectants shows rapid tau turnover in response to MB or AC. $B$, Densitometric quantitation of Western data is shown as a (evels. Greater than $50 \%$ reductions in tau levels were observed within $15 \mathrm{~min}$, and this was maintained for the levels after $1 \mathrm{~h}$ treatment with $\mathrm{Hsp70} \mathrm{MB}$ (gray) and AC (black). While decreases were seen within 5 min, significance was only achieved with MB. ${ }^{*} p<0.05,{ }^{* *} p<0.01$. E, Both total tau and pTau levels are rapidly reduced by MY (50 or $\left.100 \mu \mathrm{M}\right)$.

supranuclear palsy (PSP), we investigated whether Hsp70 inhibition could facilitate their clearance similar to wild-type tau, also drawing a comparison with Hsp90 inhibition. The tau mutants P301L, V337M, and R406W were all significantly reduced following inhibitor treatment, similar to wild-type levels (Fig. 7B). Treating cells with the Hsp90 inhibitor, 17-AAG, caused similar reductions in wt and P301L tau after $24 \mathrm{~h}$; however, V337M and R406W tau were less efficiently cleared (Fig. 7B). When all 4 tau variants were analyzed in aggregate, only Hsp70 inhibition significantly reduced tau levels (Fig. $7 B$ ). These findings confirm a difference in the mode-of-action of Hsp90 and Hsp70 inhibitors and they suggest that some tau mutants might be handled by distinct components of the chaperone system.

Fortunately, some of the Hsp70 inhibitors (MB and AC) we identified have well characterized pharmacological characteristics (e.g., stability, lifetime), which we reasoned could facilitate their use in disease models. To take advantage of this property and further explore the potential of $\mathrm{Hsp} 70$ as a therapeutic target, we investigated the impact of $\mathrm{MB}$ and $\mathrm{AC}$ on tau levels in organotypic brain slices from mice engineered to express mutant human tau (rTg4510) and age-matched wild-type littermates. In both tissue types, tau levels were significantly reduced following $3 \mathrm{~h}$ of treatment with either MB or AC (50 $\mu \mathrm{M})$ (Fig. $8 A$ ). Dramatic reductions in one pTau isoform linked to Alzheimer's disease, pS396/S404, were also evident in the rTg4510 model. Thus, nondividing neurons also realized rapid reductions in tau follow- 

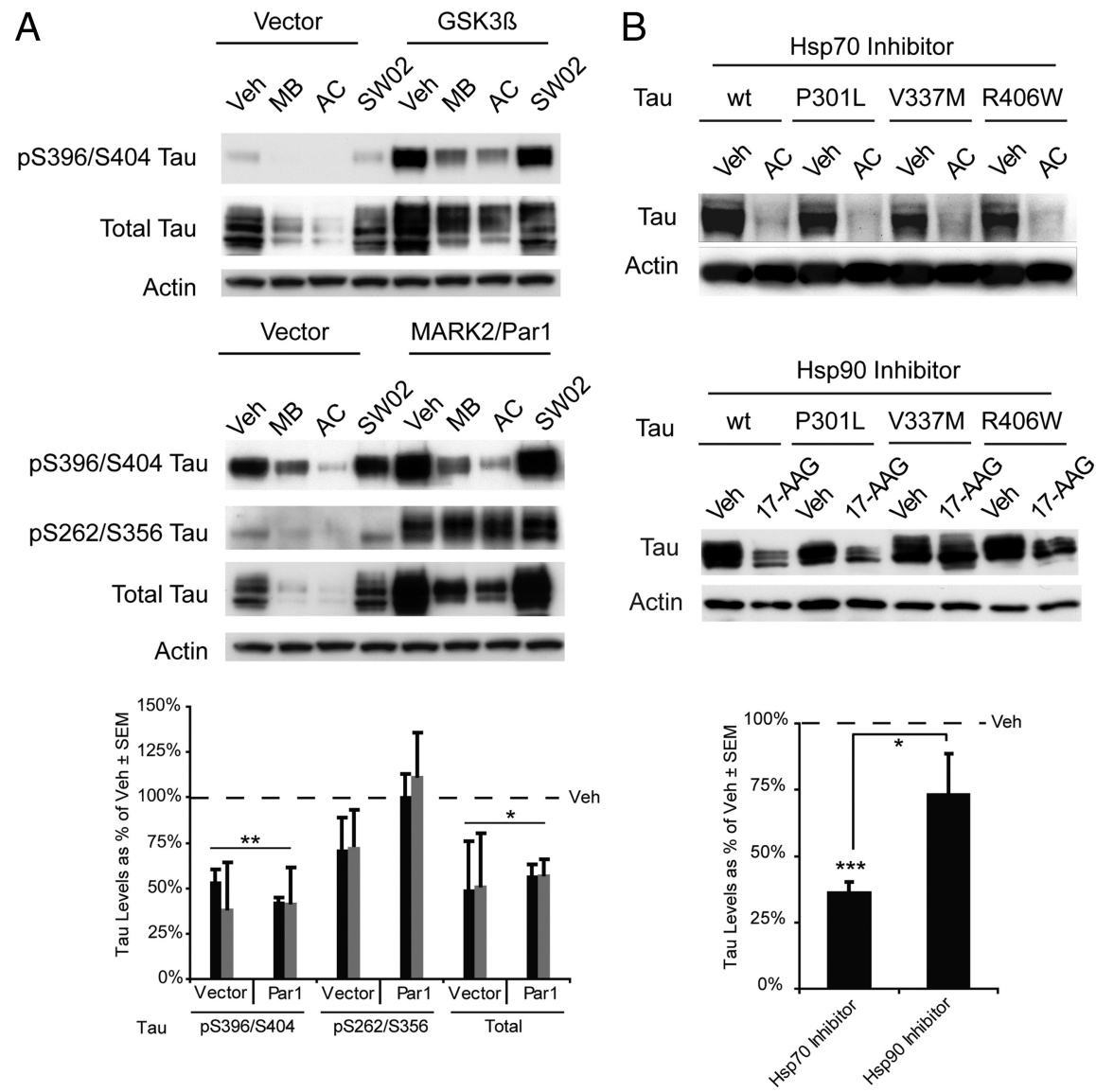

Figure 7. Phospho-tau and mutant tau species are differentially affected by Hsp70 inhibition. $A$, Levels of indicated tau species with or without overexpression of GSK3 $\beta$ or MARK2/Par1 in HeLa tau transfectants treated with Veh, MB, AC, or SW02 for $1 \mathrm{~h}$. Densitometric quantitation from replicate experiments showed that tau phosphorylated by Par1 makes pS262/S356 tau resistant to $\mathrm{Hsp} 70$ inhibition (MB; black bars and AC; gray bars). Values are presented as tau levels as a percentage of vehicle-treated cells \pm SEM. ${ }^{*} p<0.05,{ }^{* *} p<0.01$ by Student's $t$ test. $\boldsymbol{B}$, The effects of Hsp70 and Hsp90 inhibitors on tau mutants suggest that at least two chaperone pathways regulate tau processing. Treatment of transfected HeLa cells with saturating amounts of the Hsp90 inhibitor, 17-AAG, caused mild reduction in the V337M and R406W mutants, whereas AC (50 $\mu \mathrm{m})$ was able to reduce all the clinically relevant mutants by $>90 \%$. Statistical analysis comparing efficacy of either $\mathrm{Hsp} 70$ or $\mathrm{Hsp} 90$ inhibition against all four tau species revealed that Hsp70 inhibition significantly reduced tau levels in aggregate, whereas $\mathrm{Hsp90}$ inhibition did not ( $p=0.243$ ). Values are presented as tau levels as a percentage of vehicle-treated cells \pm SEM. ${ }^{*} p<0.05$, ${ }^{* * *} p<0.001$ by Student's $t$ test.

ing Hsp70 inhibition. We then directly injected AC $(2 \mu \mathrm{l}$ of 10 $\mathrm{mm}$ ) or saline into the hippocampi of eight 4-month-old rTg4510 mice and harvested these animals $24 \mathrm{~h}$ after surgery. Remarkably, these studies revealed that AC significantly and uniformly reduced soluble tau and pS396/S404 tau levels in the hippocampus (Fig. $8 \mathrm{~B}$ ). Together, these studies show that inhibitors of Hsp70 potently stimulate clearance of both normal and abnormal tau in brain tissue.

\section{Discussion}

Based on a growing body of evidence demonstrating a role for Hsp70 in modulating the stability of tau in $\mathrm{AD}$, we endeavored to identify small molecules that could directly modulate Hsp70 ATPase activity as a potential therapeutic strategy for AD. We originally hypothesized that activation of Hsp70 ATPase activity would lead to tau clearance; however, our results show quite the opposite. Inhibiting Hsp70 activity dramatically reduced tau levels, while activating it actually preserved tau levels in the cell. This paradoxical finding raised an interesting possibility: that as Hsp70 levels increase during a stress event, more Hsp70 is available to bind to unfolded substrates that result from the stress event. In tauopathies, where the accumulation of tau is gradual over time, a rapid increase in Hsp70 levels would likely lead to a reduction in tau levels simply based on stoichiometric principles; more Hsp70 is available to bind tau, decide tau's fate, and facilitate its retention or clearance. Even if a small fraction of tau is cleared by Hsp70 normally, increasing Hsp70 expression will lead to a perceived reduction in tau simply due to the increased number of Hsp70/tau complexes. Here, we show that with these new ATPase inhibitors, we can dramatically increase the fraction of Hsp70-bound tau that is cleared in circumstances where Hsp70 levels are artificially increased (Fig. 9). This explains how increasing Hsp70 levels or inhibiting its ATPase activity directly can lead to the same result: reductions in tau.

This principle highlights the most intriguing clinical aspect of this work: that transient upregulation of Hsp70 expression followed by inhibition of its ATPase activity could prove more efficacious for the treatment of $\mathrm{AD}$ and other tauopathies. As Hsp70 levels increase, it binds more tau. If we then inhibit its ATPase activity, we block its attempts to refold tau and force all of the bound tau to be released to the UPS, or other chaperone-mediated degradation pathways, for degradation. Thus, bursts of Hsp70 upregulation, perhaps by celastrol administration (Westerheide et al., 2004), followed by inhibition of its ATPase activity could prove a much more effective strategy in protein folding diseases compared with chronically enhancing either alone, or even together. This strategy would make a chemotherapeutic approach that targets the chaperones in $\mathrm{AD}$ and other neurodegenerative diseases more feasible, given the potential for side effects of drugs targeting central signaling complexes such as the Hsp70 and Hsp90 scaffolds.

In this same vein, a current concern with Hsp90 inhibitors is that they induce expression of other heat shock proteins. This is due to the role of Hsp90 as a repressor of HSF1 (heat shock factor 1 ), the major transcription factor for heat shock proteins. Once Hsp90 is inhibited, HSF1 is freed and can begin transcribing de novo heat shock proteins (Zou et al., 1998; Dickey et al., 2005). Certainly this can be viewed as either a two-pronged attack or a double-edged sword. HSF1 activation has been shown to have positive consequences in some systems of neurodegenerative disease modeling; however, chronic upregulation of heat shock proteins is likely deleterious at some level, particularly in such long-coursed diseases as AD and Huntington's disease. Because of this we speculated whether inhibiting Hsp70 at physiological levels also had a feedback consequence that regulated heat shock protein expression, perhaps providing an alternative to Hsp90 inhibition. We found that levels of heat shock proteins were not elevated following inhibition; in fact they were marginally decreased, suggesting that inhibiting Hsp70 activity promotes its clearance as well. Thus, intermittent therapy with Hsp90 inhibi- 
tors followed by Hsp70 inhibitors could prove to be a highly effective drug regimen for treating $\mathrm{AD}$ and other chronic diseases of protein misfolding.

An interesting coincidence of these data was our previous work identifying $\mathrm{MB}$ from a cell-based screening assay as a potent reducer of endogenous tau levels (Dickey et al., 2006c) and the subsequent discovery that MB was also capable of inhibiting Hsp70 ATPase function. Before the latter discovery, we described $\mathrm{MB}$ as an aggregation inhibitor, based on previous findings (Wischik et al., 1996). In fact, its efficacy as an aggregation inhibitor was what propelled AC, the demethylated analog of MB (McKamey and Spitznagle, 1975), to clinical trials as the first taubased therapy to reach patients. In light of the novel context that $\mathrm{MB}$ and $\mathrm{AC}$ inhibit Hsp70 activity, their ability to reduce endogenous tau levels has been revealed. Thus the convergence of data from two screens serendipitously led to the independent validation for each.

These compounds may also help us to better understand the role of chaperones in regulating normal tau versus pathological tau. Previous work shows that Hsp70 actually functions to enhance the association of tau with microtubules (Dou et al., 2003). Here, Hsp70 activators appear to preserve tau levels, while Hsp70 inhibitors clear tau. This would coincide nicely with a model where Hsp70 tries to protect tau from degradation, but may actually become too efficient at it, preserving even toxic tau species.

One final consideration when exploring the clinical potential of this strategy is that Hsp70 is involved in the processing of multiple substrates, especially those that are misfolded (Barral et al., 2004; Bukau et al., 2006; Balch et al., 2008). We therefore wanted to investigate the specificity of this approach. While we only tested two additional substrates that also accumulate in neurodegenerative diseases, $\alpha$-synuclein in Parkinson's disease, and TARDBP (TDP-43) in ALS, neither of these proteins were affected by drug treatment, suggesting a certain degree of selectivity of Hsp70 for tau. Certainly other disease-associated proteins that have a well established connection to Hsp70 may be affected by these compounds, such as poly-glutamine expansion diseases and prion diseases; however, the finding of some selectivity could be invaluable to the clinical viability of this strategy for AD.

In conclusion, Hsp70 is a central component of the protein folding and triage machinery, yet the mechanisms it employs to enact cellular decisions and control the fate of substrates are not yet clear. We have identified a battery of new chemical modulators of Hsp70 and used these compounds to probe how the activity of the endogenous chaperone controls tau processing. Based on these studies, we propose a model in which acute inhibition of Hsp70 might be beneficial by triggering rapid, UPS-mediated clearance of tau (Fig. 9). Moreover, we propose that the ATPhydrolysis-driven, profolding activities of the chaperone, as favored by the activator molecules, may be counterproductive under some conditions. Together, these results clarify the roles of endogenous Hsp70 in tau processing and suggest a previously unanticipated avenue for therapeutic intervention.

\section{References}

Balch WE, Morimoto RI, Dillin A, Kelly JW (2008) Adapting proteostasis for disease intervention. Science 319:916-919.

Barral JM, Broadley SA, Schaffar G, Hartl FU (2004) Roles of molecular chaperones in protein misfolding diseases. Semin Cell Dev Biol 15:17-29.

Berger Z, Roder H, Hanna A, Carlson A, Rangachari V, Yue M, Wszolek Z, Ashe K, Knight J, Dickson D, Andorfer C, Rosenberry TL, Lewis J, Hutton M, Janus C (2007) Accumulation of pathological tau species and memory loss in a conditional model of tauopathy. J Neurosci 27:3650-3662.

Boulton DW, Walle UK, Walle T (1999) Fate of the flavonoid quercetin in human cell lines: chemical instability and metabolism. J Pharm Pharmacol 51:353-359.

Braak H, Braak E (1991) Neuropathological stageing of Alzheimer-related changes. Acta Neuropathol 82:239-259.

Brehmer D, Rüdiger S, Gässler CS, Klostermeier D, Packschies L, Reinstein J, Mayer MP, Bukau B (2001) Tuning of chaperone activity of Hsp70 proteins by modulation of nucleotide exchange. Nat Struct Biol 8:427-432.

Bukau B, Weissman J, Horwich A (2006) Molecular chaperones and protein quality control. Cell 125:443-451.

Carrettiero DC, Hernandez I, Neveu P, Papagiannakopoulos T, Kosik KS (2009) The cochaperone BAG2 sweeps paired helical filament-insoluble tau from the microtubule. J Neurosci 29:2151-2161.

Chang L, Bertelsen EB, Wisén S, Larsen EM, Zuiderweg ER, Gestwicki JE (2008) High-throughput screen for small molecules that modulate the ATPase activity of the molecular chaperone DnaK. Anal Biochem 372:167-176.

Davidson GA, Varhol RJ (1995) Kinetics of thapsigargin-Ca(2+)-ATPase 
Neuronal damage leads to loss of MT function for tau

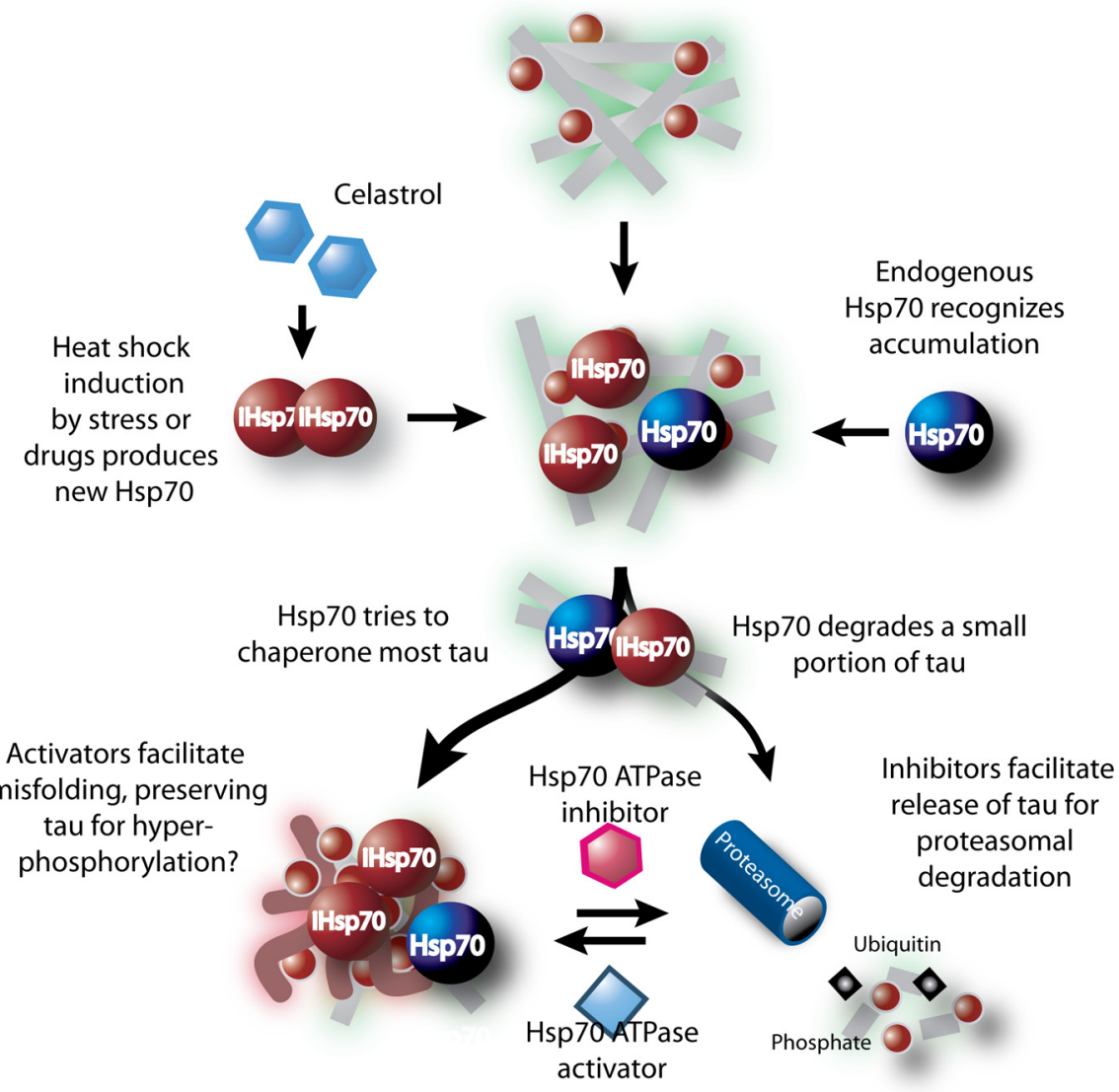

Figure 9. Altering the cellular decision to fold or degrade: a model for Hsp70-mediated control of tau stability. Based on the results of this study, we propose that the ATPase activity of $\mathrm{Hsp} 70$ plays a critical role in governing tau fate. Specifically, pharmacological activation of ATPase activity favors formation of a profolding complex that causes net accumulation of tau and perhaps misfolding. Conversely, inhibition of ATP turnover enhances coupling to the UPS system. In this model, overexpression of Hsp70 does not intrinsically alter the balance of folding/degradation and, only after concurrent treatment with inhibitors, is the decision made to degrade tau. Artificially increasing the amount of $\mathrm{Hsp} 70$ either genetically (induced Hsp70) or pharmacologically with drugs like celastrol, provides more Hsp70/tau complexes for Hsp70 ATPase compounds to affect.

(sarcoplasmic reticulum) interaction reveals a two-step binding mechanism and picomolar inhibition. J Biol Chem 270:11731-11734.

Dickey CA, Eriksen J, Kamal A, Burrows F, Kasibhatla S, Eckman CB, Hutton M, Petrucelli L (2005) Development of a high throughput drug screening assay for the detection of changes in tau levels - proof of concept with HSP90 inhibitors. Curr Alzheimer Res 2:231-238.

Dickey CA, Dunmore J, Lu B, Wang JW, Lee WC, Kamal A, Burrows F, Eckman C, Hutton M, Petrucelli L (2006a) HSP induction mediates selective clearance of tau phosphorylated at proline-directed Ser/Thr sites but not KXGS (MARK) sites. FASEB J 20:753-755.

Dickey CA, Yue M, Lin WL, Dickson DW, Dunmore JH, Lee WC, Zehr C, West G, Cao S, Clark AM, Caldwell GA, Caldwell KA, Eckman C, Patterson C, Hutton M, Petrucelli L (2006b) Deletion of the ubiquitin ligase CHIP leads to the accumulation, but not the aggregation, of both endogenous phospho- and caspase-3-cleaved tau species. J Neurosci 26:6985-6996.

Dickey CA, Ash P, Klosak N, Lee WC, Petrucelli L, Hutton M, Eckman CB (2006c) Pharmacologic reductions of total tau levels; implications for the role of microtubule dynamics in regulating tau expression. Mol Neurodegener 1:6.

Dickey CA, Kamal A, Lundgren K, Klosak N, Bailey RM, Dunmore J, Ash P, Shoraka S, Zlatkovic J, Eckman CB, Patterson C, Dickson DW, Nahman NS Jr, Hutton M, Burrows F, Petrucelli L (2007) The high-affinity HSP90-CHIP complex recognizes and selectively degrades phosphorylated tau client proteins. J Clin Invest 117:648-658.

Dickey CA, Koren J, Zhang YJ, Xu YF, Jinwal UK, Birnbaum MJ, Monks B,
Sun M, Cheng JQ, Patterson C, Bailey RM, Dunmore J, Soresh S, Leon C, Morgan D, Petrucelli L (2008) Akt and CHIP coregulate tau degradation through coordinated interactions. Proc Natl Acad Sci U S A 105:36223627.

Dou F, Netzer WJ, Tanemura K, Li F, Hartl FU, Takashima A, Gouras GK, Greengard P, Xu H (2003) Chaperones increase association of tau protein with microtubules. Proc Natl Acad Sci U S A 100:721-726.

Frautschy SA, Baird A, Cole GM (1991) Effects of injected Alzheimer beta-amyloid cores in rat brain. Proc Natl Acad Sci U S A 88:83628366.

Hardy J, Orr H (2006) The genetics of neurodegenerative diseases. J Neurochem 97:16901699.

Järv J, Hedlund B, Bartfai T (1980) Kinetic studies on muscarinic antagonist-agonist competition. J Biol Chem 255:2649-2651.

Josephs KA, Whitwell JL, Knopman DS, Hu WT, Stroh DA, Baker M, Rademakers R, Boeve BF, Parisi JE, Smith GE, Ivnik RJ, Petersen RC, Jack CR Jr, Dickson DW (2008) Abnormal TDP-43 immunoreactivity in AD modifies clinicopathologic and radiologic phenotype. Neurology 70:1850-1857.

Luo W, Dou F, Rodina A, Chip S, Kim J, Zhao Q, Moulick K, Aguirre J, Wu N, Greengard P, Chiosis G (2007) Roles of heat-shock protein 90 in maintaining and facilitating the neurodegenerative phenotype in tauopathies. Proc Natl Acad Sci U S A 104:9511-9516.

Mayer MP, Schröder H, Rüdiger S, Paal K, Laufen T, Bukau B (2000) Multistep mechanism of substrate binding determines chaperone activity of Hsp70. Nat Struct Biol 7:586-593.

McKamey MR, Spitznagle LA (1975) Chromatographic, mass spectral, and visible light absorption characteristics of toluidine blue $\mathrm{O}$ and related dyes. J Pharm Sci 64:1456-1462.

Mirnikjoo B, Brown SE, Kim HF, Marangell LB, Sweatt JD, Weeber EJ (2001) Protein kinase inhibition by omega-3 fatty acids. J Biol Chem 276:10888-10896.

Mukaetova-Ladinska EB, Garcia-Siera F, Hurt J, Gertz HJ, Xuereb JH, Hills R, Brayne C, Huppert FA, Paykel ES, McGee M, Jakes R, Honer WG, Harrington CR, Wischik CM (2000) Staging of cytoskeletal and beta-amyloid changes in human isocortex reveals biphasic synaptic protein response during progression of Alzheimer's disease. Am J Pathol 157:623-636.

Neckers L (2002) Hsp90 inhibitors as novel cancer chemotherapeutic agents. Trends Mol Med 8:S55-61.

Oddo S, Caccamo A, Shepherd JD, Murphy MP, Golde TE, Kayed R, Metherate R, Mattson MP, Akbari Y, LaFerla FM (2003) Triple-transgenic model of Alzheimer's disease with plaques and tangles: intracellular Abeta and synaptic dysfunction. Neuron 39:409-421.

Pellecchia M, Montgomery DL, Stevens SY, Vander Kooi CW, Feng HP, Gierasch LM, Zuiderweg ER (2000) Structural insights into substrate binding by the molecular chaperone DnaK. Nat Struct Biol 7:298-303.

Petrucelli L, Dickson D, Kehoe K, Taylor J, Snyder H, Grover A, De Lucia M, McGowan E, Lewis J, Prihar G, Kim J, Dillmann WH, Browne SE, Hall A, Voellmy R, Tsuboi Y, Dawson TM, Wolozin B, Hardy J, Hutton M (2004) CHIP and Hsp70 regulate tau ubiquitination, degradation and aggregation. Hum Mol Genet 13:703-714.

Roberson ED, Scearce-Levie K, Palop JJ, Yan F, Cheng IH, Wu T, Gerstein H Yu GQ, Mucke L (2007) Reducing endogenous tau ameliorates amyloid beta-induced deficits in an Alzheimer's disease mouse model. Science 316:750-754.

Rutherford NJ, Zhang YJ, Baker M, Gass JM, Finch NA, Xu YF, Stewart H, Kelley BJ, Kuntz K, Crook RJ, Sreedharan J, Vance C, Sorenson E, 
Lippa C, Bigio EH, Geschwind DH, Knopman DS, Mitsumoto H, Petersen RC, Cashman NR, et al. (2008) Novel mutations in TARDBP (TDP-43) in patients with familial amyotrophic lateral sclerosis. PLoS Genet 4:e1000193.

Salzmann M, Pervushin K, Wider G, Senn H, Wüthrich K (1998) TROSY in triple-resonance experiments: new perspectives for sequential NMR assignment of large proteins. Proc Natl Acad Sci U S A 95:13585-13590.

Shimura H, Schwartz D, Gygi SP, Kosik KS (2004a) CHIP-Hsc70 complex ubiquitinates phosphorylated tau and enhances cell survival. J Biol Chem 279:4869-4876.

Shimura H, Miura-Shimura Y, Kosik KS (2004b) Binding of tau to heat shock protein 27 leads to decreased concentration of hyperphosphorylated tau and enhanced cell survival. J Biol Chem 279:17957-17962.

Slepenkov SV, Witt SN (2002) The unfolding story of the Escherichia coli Hsp70 DnaK: is DnaK a holdase or an unfoldase? Mol Microbiol 45:1197-1206.

Ward NE, O’Brian CA (1992) Kinetic analysis of protein kinase C inhibition by staurosporine: evidence that inhibition entails inhibitor binding at a conserved region of the catalytic domain but not competition with substrates. Mol Pharmacol 41:387-392.

Westerheide SD, Bosman JD, Mbadugha BN, Kawahara TL, Matsumoto G, Kim S, Gu W, Devlin JP, Silverman RB, Morimoto RI (2004) Celastrols as inducers of the heat shock response and cytoprotection. J Biol Chem 279:56053-56060.

Wilcock DM, Alamed J, Gottschall PE, Grimm J, Rosenthal A, Pons J, Ronan V, Symmonds K, Gordon MN, Morgan D (2006) Deglycosylated antiamyloid-beta antibodies eliminate cognitive deficits and reduce parenchymal amyloid with minimal vascular consequences in aged amyloid precursor protein transgenic mice. J Neurosci 26:5340-5346.

Winton MJ, Van Deerlin VM, Kwong LK, Yuan W, Wood EM, Yu CE, Schellenberg GD, Rademakers R, Caselli R, Karydas A, Trojanowski JQ, Miller BL, Lee VM (2008) A90V TDP-43 variant results in the aberrant localization of TDP-43 in vitro. FEBS Lett 582:2252-2256.

Wischik CM, Edwards PC, Lai RY, Roth M, Harrington CR (1996) Selective inhibition of Alzheimer disease-like tau aggregation by phenothiazines. Proc Natl Acad Sci U S A 93:11213-11218.

Wisén S, Androsavich J, Evans CG, Chang L, Gestwicki JE (2008) Chemical modulators of heat shock protein 70 (Hsp70) by sequential, microwaveaccelerated reactions on solid phase. Bioorg Med Chem Lett 18:60-65.

Zou J, Guo Y, Guettouche T, Smith DF, Voellmy R (1998) Repression of heat shock transcription factor HSF1 activation by HSP90 (HSP90 complex) that forms a stress-sensitive complex with HSF1. Cell 94:471-480.

Zuiderweg ER (2002) Mapping protein-protein interactions in solution by NMR spectroscopy. Biochemistry 41:1-7. 